\title{
DILEMAS E DESAFIOS DA PARTICIPAÇÃO SOCIAL NOS CONSELHOS DE SAÚDE NO BRASIL
}

\author{
DILEMMAS AND CHALLENGES OF SOCIAL PARTICIPATION IN \\ HEALTH COUNCILS IN BRAZIL
}

Cilânea dos Santos Costa ${ }^{1}$

\begin{abstract}
RESUMO: OBJETIVO: O presente estudo tem por objetivo fazer uma breve discussão sobre modelo de participação social que se tem desenhado no âmbito da Política de Saúde, através dos Conselhos de Saúde, mecanismos de controle social e ampliação da cidadania, criados a partir da Constituição Federal de 1988. O direito a participação social na saúde é fruto de um intenso debate construído durante o Movimento Sanitário o qual lutava pela democratização da saúde, em contraponto ao modelo privatista em vigência. Tendo em vista, que na atualidade vivenciamos um processo de desconstrução de direitos, em virtude do ideal neoliberal, instalado no País na década de 1990. MÉTODO: optou-se por uma pesquisa de cunho bibliográfico com abordagem qualitativa, cujo método se debruça no dialético, pois este oferece subsídios para a análise do objeto de estudo e seus determinantes. RESULTADOS: Diante disso, ficou evidente que os Conselhos de Saúde não tem se configurado como canal democrático dentro da relação entre Estado e Sociedade civil, ainda vigoram práticas que caminham para rotinização, manipulação política e burocratização em seu funcionamento. CONCLUSÃO: A participação social é indispensável para legitimação das demandas coletivas, torna-se cada vez mais imprescindível que os sujeitos sociais se apropriem desses espaços de participação direta e contribuam na construção do planejamento orçamentário, bem como seu monitoramento, implementação e fiscalização.
\end{abstract}

Palavras chave: Conselhos de saúde. Direito a saúde. Participação Social. Política de Saúde.

ABSTRACT: OBJECTIVE: The purpose of this study is to make a brief discussion about the model of social participation that has been designed within the scope of

\footnotetext{
${ }^{1}$ Assistente Social graduada pela Universidade Estadual da Paraíba (UEPB). Especialista em Gestão Pública (UEPB), possui Residência Multiprofissional em Saúde Materno-Infantil da Universidade Federal do Rio Grande do Norte (UFRN). Atualmente é residente em Saúde Coletiva com Ênfase em Gestão de Redes de Saúde pela Escola de Governo em Saúde Pública de Pernambuco - ESPPE
} 
Health Policy, through the Health Councils, mechanisms of social control and expansion of citizenship, created from the Constitution Federal of 1988. The right to social participation in health is the result of an intense debate built during the Sanitary Movement which fought for the democratization of health, in contrast to the current privatist model. Bearing in mind that, today, we are experiencing a process of deconstruction of rights, due to the neoliberal ideal, installed in the country in the 1990. METHOD: we opted for a bibliographic research with a qualitative approach, whose method focuses on the dialectic, since it offers subsidies for an analysis of the object of study and its determinants. RESULTS: In view of this, it was evident that the Health Councils have not been configured as a democratic channel within the relationship between the State and civil society, there are still practices that move towards routinization, political manipulation and bureaucratization in their functioning. CONCLUSION: Social participation is indispensable for legitimizing collective demands, it is becoming increasingly essential that social subjects take ownership of these spaces for direct participation and contribute to the construction of budget planning, as well as their monitoring, implementation and inspection.

Keywords: Health Councils. Right to Health. Social Participation. Health Policy. 


\title{
INTRODUÇÃO
}

O presente artigo é fruto da monografia apresentada ao Programa de Pós graduação em Gestão Pública da Universidade Estadual da Paraíba, teve por objetivo refletir sobre a participação social a partir dos conselhos de saúde, evidenciando os principais desafios para efetivação desse direito e as possibilidades que esse espaço dispõe para o exercício da cidadania e consequente assegurando o direito humano fundamental a saúde.

No Brasil, o debate acerca da democratização das políticas sociais ganham relevo na década de 1980, com o ressurgimento dos movimentos sociais que passam a lutar pela redefinição das relações entre Estado e sociedade civil, consta desse período significativas vitórias no campo social, conforme destaca Raichelis (2009).

\begin{abstract}
Este movimento põe em discussão não apenas o padrão histórico que tem caracterizado a realização das políticas sociais em nosso país, seletivo, fragmentado, excludente e setorizado, mas também a necessidade de democratização dos processos decisórios responsáveis pela definição de prioridades e modos de gestão de políticas e programas sociais (RAICHELIS, 2009, p. 77).
\end{abstract}

Destacadamente a saúde nosso objeto de estudo, temos a promulgação das Leis Orgânicas da Saúde (LOS), n8080/90 e n 8.142/90, que além de regulamentar as determinações do texto constitucional, trazem os aspectos relacionados a organização e funcionamento do sistema único de saúde, bem como a descentralização das ações e serviços de saúde, os papeis e atribuições dos gestores nas esferas de governo e nos níveis de atenção á saúde. Consagram ainda, o financiamento da política e os seus respectivos critérios de repasses dos recursos para o âmbito estadual e municipal, além de orientar o controle social nas três esferas gestoras do SUS (BRASIL, 1991b). 


\section{METODOLOGIA}

O estudo se desenvolveu a partir de uma pesquisa teórica, sendo esta "dedicada a reconstruir teoria, conceitos, ideias, ideologias, polêmicas, tendo em vista, em termos imediatos, aprimorar fundamentos teóricos" (Demo, 2000, p. 20). Tendo em vista que tal procedimento visa identificar conhecimentos prévios acerca do objeto que será analisado, esse tipo de pesquisa tem como premissa:

Fundamentar teoricamente o objeto de estudo, contribuindo com elementos que subsidiam a análise futura dos dados obtidos. Portanto, difere da revisão bibliográfica uma vez que vai além da simples observação de dados contidos nas fontes pesquisadas, pois imprime sobre eles a teoria, a compreensão crítica do significado neles existente. (LIMA; MIOTO, 2007, p. 44)

O trabalho privilegiou a abordagem qualitativa, cujo método se debruça no dialético, pois este oferece subsídios para a análise do objeto de estudo e seus determinantes. A pesquisa dialética oferece "as bases para uma interpretação dinâmica e totalizante da realidade, uma vez que estabelece que os fatos sociais não podem ser entendidos quando considerados isoladamente, abstraídos de suas influências políticas, econômicas, culturais etc" ( GIL, 2008, p.14).

Dessa forma, pontua-se que a pesquisa de cunho bibliográfico como um procedimento metodológico é de extrema relevância na produção do conhecimento científico capaz de suscitar, especialmente em temas pouco explorados, a elaboração de hipóteses ou interpretações que nortearão futuras pesquisas (LIMA; MIOTO, 2007).

Para tanto, procurou-se desenvolver algumas reflexões acerca do controle social exercido através dos conselhos de saúde, evidenciando seus principais desafios e possibilidades. 


\section{RESULTADOS}

Historicamente, o controle social esteve relacionado apenas ao controle do Estado e do empresariado sobre a população, dentro de uma perspectiva coercitiva, dominante. O termo escrito na Constituição de 1988 revela o controle social, enquanto participação da sociedade na elaboração, implementação e fiscalização das políticas sociais. (BRAVO, 2012). No plano jurídico, o controle social na saúde foi regulamentado pela Lei ${ }^{\circ} 8.142 / 90$ estabelece dois espaços para o exercício do controle social na gestão do SUS: as Conferências e os Conselhos de Saúde. As Conferências correspondem a fóruns amplos, realizadas de quatro em quatro anos com a participação representantes da sociedade usuários do SUS, profissionais de saúde, representantes do governo, prestadores de serviços de saúde, e outros, para avaliar a situação de saúde e propor as diretrizes para a formulação da política de saúde nas três esferas de governo (BRASIL, 1991b). "As deliberações das conferências devem ser entendidas enquanto norteadoras da implantação das políticas e, portanto, influenciar as discussões travadas nos diversos conselhos" (BRAVO, 2009b, p.4).

No que diz respeito ao outro instrumento de participação da sociedade civil temos os Conselhos de Saúde que conforme preceitua (BRASIL, 2003) corresponde a um é órgão colegiado, deliberativo e permanente do Sistema Único de Saúde (SUS) presente em cada esfera de Governo, integrante da estrutura básica do Ministério da Saúde, da Secretaria de Saúde dos Estados, do Distrito Federal e dos Municípios. Conforme assevera Raichelis (2009, p.83):

Os Conselhos são canais importantes de participação coletiva e de criação de novas relações políticas entre governos e cidadãos e, principalmente, de construção de um processo continuado de interlocução pública. Por meio desta interlocução objetiva-se propor alternativas de políticas públicas, criar espaços de debate, estabelecer mecanismos de negociação e pactuação, penetrar a lógica burocrática estatal para transformá-la e exercer o controle socializado das ações e deliberações governamentais. 
Os conselhos surgem como um constructo institucional em contraponto tendência clientelista, patrimonialista e autoritária que perpassa a construção e desenvolvimento do estado brasileiro. Diante disso, os conselhos se propõem a modificar essa relação, vislumbra-se a partir destes a construção de esferas públicas autônomas, democráticas, transparentes no trato da gestão pública, de forma que os interesses particularistas e corporativistas sejam ultrapassados pelos interesses coletivos e suas reais demandas sociais (RAICHELIS, 2009).

Dentro da perspectiva de descentralização da política de saúde, que corresponde a redistribuição de responsabilidade entre os três níveis de governo, os conselhos juntamente com os fundos e planos de saúde são requisitos legais para o repasse de recursos da esfera federal para as estaduais e municipais. Tendo em vista esses elementos muitos conselhos foram criados visando a mera formalização para garantia de recursos, se configurando em um canal de legitimação de estratégias manipuladoras da gestão em seus diversos níveis.

De acordo com Bravo (2009b), destaca que os conselhos estão na contramão do processo histórico conjuntural ao passo que vivenciamos uma conjuntura de desmobilização da participação social sendo evidente a minimização do papel do Estado frente às políticas sociais, como preconiza o neoliberalismo. Dessa forma, os conselhos podem contribuir para reforçar ações de desresponsabilização do Estado.

Em sintonia com essa tendência Correia (2009), destaca que a efetivação do controle social no campo dos Conselhos tem se mostrado limitada, em virtude da não transparência dos gestores, tanto no nível do fornecimento de informações da própria gestão, como na manipulação de dados epidemiológicos, é comum o uso de artifícios contábeis na administração dos recursos do fundo de saúde, forte estratégia nas escolhas dos conselheiros, forte relação de poder, com manipulação dos conselheiros de saúde na aprovação das propostas da gestão. Reforça ainda a autora que no tocante a participação dos usuários, verifica-se a fragilidade política das entidades representadas, com ínfima organicidade entre representantes e representados, pela ausência de articulação deste segmento na defesa de propostas em termos de um projeto comum, forte corporativismo de cada conselheiro sendo recorrente a visão de defesa dos interesses ligados a sua entidade, além da 
fragilidade na divulgação e acesso às informações, seja pelo desconhecimento sobre seu papel e ou pela realidade da saúde na qual está inserido.

Corroborando com o exposto, Bravo (2012) trazem mais elementos para o debate quando se referem aos entraves para o pleno exercício do controle social na saúde no âmbito dos conselhos destacam como pontos dessa arena de tensões e disputas:

A concepção de democracia restrita ao aparelho do Estado (participação consentida); concepção dos conselhos como: espaços de consenso, espaços para controlar os conflitos; mecanismos de viabilização das ações do Estado com consentimento da população, parceria entre Estado e sociedade; populismo e cooptação dos conselhos pela burocracia do estado; fragmentação da questão social em múltiplos conselhos com a participação reduzida da sociedade (os mesmo sujeitos políticos participando de diversos conselhos); apropriação dos conselhos pelo gestor e perda de diálogo com a sociedade (BRAVO, 2012, p.64).

O fato é que na sociedade brasileira desde a sua formação sócio-histórica presencia-se uma manipulação dos fundos públicos sem esfera pública, ou seja, sem regras que privilegie e estejam em sintonia com as demandas dos setores sociais. No campo da política de saúde, o descompasso entre a efetivação do que está assegurado no aparato jurídico e o potencial desfinanciamento que acomete veemente esse bem público, que na atualidade tem encontrado na arena do judiciário espaço para sua concretização, através da judicialização.

O direito à informação pública compreende um direito humano fundamental, indispensável para o processo democrático, consubstanciando também em uma via para o fortalecimento da cidadania tendo vista o controle da gestão pública pela sociedade.

O marco brasileiro nesse campo corresponde a promulgação da Lei 12.527 de 18 de novembro de 2011, a lei estabelece uma mudança de paradigma no cenário da transparência pública brasileira, ao passo que define o acesso como regra e o sigilo como exceção.

O direito a informação concebido enquanto bem público, vem sendo construído e assegurado internacionalmente através de diversas convenções e tratados assinados pelo Brasil. Vejamos como preceitua no plano internacional a 
garantia desse direito. Na Declaração Universal dos Direitos Humanos, em seu artigo 19: "Todo ser humano tem direito à liberdade de opinião e expressão; este direito inclui a liberdade de, sem interferência, ter opiniões e de procurar, receber e transmitir informações e ideias por quaisquer meios e independentemente de fronteiras" (UNESCO, 2014).

No que concerne a Convenção das Nações Unidas Contra a Corrupção, ratificada pelo Brasil, esta versa no tocante ao direito a informação em seu artigo 10 que:

Tendo em conta a necessidade de combater a corrupção, cada Estado Parte, em conformidade com os princípios fundamentais de sua legislação interna, adotará medidas que sejam necessárias para aumentar a transparência em sua administração pública, inclusive no relativo a sua organização, funcionamento e processos de adoção de decisões, quando proceder. (CGU, 2008, p.30).

Destaca ainda em seu artigo 13, que o Estado deve promover a participação ativa das pessoas e grupos que não estejam ligados na gestão do setor público, de forma que contribuam na prevenção e na luta contra a corrupção (CGU, 2008).

Ainda no plano internacional, a Declaração de Princípios sobre Liberdade de Expressão destaca que em seus princípios que o acesso a informação é um direito fundamental do individuo e os Estados tem a obrigação de garantir o pleno exercício desse direito.

Ressalta ainda o Pacto Internacional dos Direitos Civis e Políticos em seu artigo 19 , inciso $2^{\circ}$, que toda pessoa, independente das fronteiras tem direito à liberdade de expressão; o que inclui a liberdade de procurar, receber e difundir informações e ideias de qualquer natureza.

No ordenamento nacional, a nossa Constituição de 1988, traz em seu capítulo I, que versa sobre os Direitos e Deveres Individuais e Coletivos, destacadamente o inciso XXXIII do artigo 5 que:

Todos têm direito a receber dos órgãos públicos informações de seu interesse particular, ou de interesse coletivo ou geral, que serão prestadas no prazo da lei, sob pena de responsabilidade, ressalvadas aquelas cujo sigilo seja 
imprescindível à segurança da sociedade e do Estado. (BRASIL, 1988).

A Lei 12.527/11 vem regulamentar o que dispõe o texto constitucional quando consolida e define que o acesso à informação pública está sob guarda do Estado em nome da sociedade deve estabelecer procedimentos para que a administração pública responda aos pedidos de informação do cidadão, bem como assegura que o acesso à informação pública é a regra, e o sigilo, a exceção. Dessa forma, a informação produzida, guardada, organizada ou gerenciada pelo Estado é considerada um bem público (CGU, 2011). Devendo ser restringida apenas em casos específicos, de acordo com a sua classificação, sendo pela respectiva lei dividida em ultrassecreta, secreta ou reservada, o que não impede o seu acesso com o decorrer dos anos, a ultrassecreta: 25 (vinte e cinco) anos; a secreta: 15 (quinze) anos; e a reservada: 5 (cinco) anos (BRASIL, 2011).

A classificação do sigilo de informações no âmbito da administração pública federal é de competência, segundo o artigo 27 da citada lei, no grau de ultrassecreto, do Presidente da República; Vice-Presidente da República; Ministros de Estado e autoridades com as mesmas prerrogativas; Comandantes da Marinha, do Exército e da Aeronáutica; e Chefes de Missões Diplomáticas e Consulares permanentes no exterior. No grau secreto temos a competência das autarquias, fundações ou empresas públicas e sociedades de economia mista. No grau reservado, temos as autoridades supracitadas, mais as que exerçam funções de direção, comando ou chefia, nível DAS 101.5, ou superior, do Grupo-Direção e Assessoramento Superiores, ou de hierarquia equivalente, de acordo com regulamentação específica de cada órgão ou entidade (BRASIL, 2011).

Diante do exposto, evidencia-se o nível de importância que a lei de acesso a informação traz para o fortalecimento controle social, tendo em vista que a sociedade de posse das informações públicas tem possibilidade de ampliação no processo decisório da gestão pública. 


\section{CONSIDERAÇÕES FINAIS}

Com base no exposto, compreendemos que os Conselhos de Saúde não tem se configurado como canal democrático dentro da relação entre Estado e Sociedade civil, ainda vigoram práticas que caminham para rotinização, manipulação política e burocratização em seu funcionamento. Seu caráter fiscalizador, deliberativo e de decisão compartilhada tem sido fragilizado e tensionado pelas decisões unilaterais das gestões, o que por sua vez, não representa as reais demandas da coletividade.

Como adverte Raichelis (2009) é presente em todos os níveis de gestão, a sonegação de informações, a escolha de representantes sem um processo eleitoral democrático, havendo cooptação dos conselheiros sendo recorrentes as presidências impostas.

O fato é que esses espaços de participação social enquanto, instrumento de interlocução e diálogo, arena de construção de propostas e vocalizador dos interesses e reivindicações da sociedade tem se mostrado como lócus de poder da gestão, muitas das vezes sem transparência e democratização das informações e com frágil representatividade e participação social.

É oportuno rememorar que esses mecanismos de controle democráticos criados a partir da Constituição de 1988 e implementados na década de $90 \mathrm{com}$ as leis orgânicas de saúde vão sofrer os embates da ideologia neoliberal que se instala no Brasil a partir dessa década, preconizando essa, a redução dos direitos sociais e trabalhistas, o desmonte das políticas de previdência, educação e destacadamente a de saúde, com indução do acesso a saúde pela via privada, através de ampliação dessa rede de serviços, acenando para privatização e terceirização dos serviços de saúde, diante desse cenário político e econômico que prega a desresponsabilização do Estado frente às questões sociais incidirá fortemente na despolitização dos interesses coletivos dentro da esfera pública, o que por sua vez acarreta a debilidade dos espaços de representação coletiva e controle social.

Diante desse cenário de regressão de direitos e fragilidade na gestão democrática das políticas sociais, urge o desafio de qualificar essa representação 
com ampliação dessa participação, para tanto Bravo (2012), destaca como estratégias:

Democratização das informações relativas a saúde; Realização de encontros populares de saúde e ou pré - conferências; Rearticulação dos Conselhos Comunitários de Saúde e ou Fóruns Populares de Políticas Sociais; Implantação ou rearticulação dos Conselhos Gestores de Unidades; Mobilização das entidades dos profissionais de saúde para participarem dos conselhos; Elaboração dos planos de saúde com a participação dos sujeitos sociais; Mobilização e ou iniciativas para modificar a composição dos Conselhos não paritários; Articulação entre conselheiros representantes dos usuários e trabalhadores de saúde e capacitação dos conselheiros na perspectiva crítica e propositiva (BRAVO, 2012, p. 65).

A verdade é que esse retrocesso histórico no acesso aos serviços de saúde implicará como já foi mencionado na sua crescente judicialização, o que podemos ver que carregam questões que extrapolam o espaço jurídico, envolvem fatores de ordem econômica, financeira, gestão e participação social, sem o exame dessa densa totalidade de determinantes não é possível compreender como, atualmente se efetiva o direito fundamental á saúde no Brasil.

A participação social é indispensável para legitimação das demandas coletivas, torna-se cada vez mais imprescindível que os sujeitos sociais se apropriem desses espaços de participação direta e contribuam na construção desses instrumentos do planejamento orçamentário como LOA, PPA, LDO, bem como seu monitoramento, implementação e fiscalização. "Participação não para discutir o planejamento com técnicos, mas para beneficiar-se do planejamento programado em razão de sua força no contexto de poder" (GOHN, 2011, p.57).

Como bem preceitua Bobbio (1992), "o problema dos direitos, na atualidade não é justificá-los, mas de protegê-los". A via para concretização desses direitos reside na ampliação da participação democrática, de forma que pressione o Estado para que forneça os meios de respeitar, proteger e promover a viabilização desses direitos historicamente construídos. 


\section{REFERÊNCIAS BIBLIOGRÁFICAS}

BRASIL, CONSTITUIÇÃO DA REPÚBLICA FEDERATIVA DO BRASIL, Brasília: Senado Federal, 1988.

Lei de acesso a informação $\mathrm{n}^{\circ}$ 12.527/2011. Disponível em: http://www.planalto.gov.br/ccivil_03/_ato2011-2014/2011/lei//12527.htm .Acessado em: 18 de abril de 2015.

Brasília, 1991a.

Ministério da Saúde. Lei Orgânica da Saúde. Lei n. ${ }^{8} 8080$ de 19 de setembro de 1990 -

Ministério da Saúde. Lei Orgânica da Saúde. Lei n. ${ }^{\circ} 8142$ de 28 de dezembro de 1990 - Brasilia, 1991b.

.Ministério da Saúde. Conselho Nacional de Saúde. Resolução n. 333 , de 4 de novembro de 2003. Aprovar as seguintes diretrizes para criação, reformulação, estruturação e funcionamento dos Conselhos de Saúde. Revogada as Resoluções 33/1992 e a de n. ${ }^{\circ}$ 319/2002. Diário Oficial da União, Brasília, DF, dez. 2003.

Ministério da Saúde. Secretaria de Vigilância em Saúde. Manual de direito sanitário com enfoque na vigilância em saúde / Ministério da Saúde, Secretaria de Vigilância em Saúde. Brasília: Ministério da Saúde, 2006.

BRAVO, M. I. S. O trabalho do assistente social nas instâncias públicas de controle democrático. In: CFESS-ABEPSS. Serviço Social: direitos sociais e competências profissionais. Brasília: Cfess/Abepss, 2009.

Gestão Democrática na Saúde: o potencial dos conselhos. In: BRAVO, Maria Inês Souza; PEREIRA, Potyara, A. P. (Org.). Política Social e Democracia. $5^{a}$ ed. São Paulo: Cortez; Rio de Janeiro: UERJ, 2012.

BOBBIO, Norberto. A era dos direitos. Trad. Carlos Nelson Coutinho. Rio de Janeiro: Campus, 1992.

CGU, Controladoria Geral da União. Orientações aos cidadãos para participação na gestão pública e exercício do controle social. CGU, Brasília, 2010.

Acesso à Informação Pública: uma introdução à Lei $n .12527$, de 18 de novembro de 2011. Brasília: CGU.

COHN. A. Conselhos gestores e participação sociopolítica. 4. ed. São Paulo: Cortez, 2011.

CORREIA. M. V. C. Controle Social na Saúde. In: MOTA, A. E. et al. (orgs.). Serviço Social e Saúde: formação e trabalho profissional. $2^{a}$ ed. São Paulo: OPAS, OMS, Ministério da Saúde, 2009.

CONTROLADORIA GERAL DA UNIÃO. Controle Social Orientações aos cidadãos para participação na gestão pública e exercício do controle social. Coleção Olho Vivo, Brasília, 2010.

DEMO, P. Metodologia do conhecimento científico. São Paulo: Atlas, 2000.

GIL, A. C. Métodos e técnicas de pesquisa social. 6. ed. São Paulo: Atlas, 2008. 
LIMA, T. C. S.; MIOTO, R. C. T. Procedimentos metodológicos na construção do conhecimento científico: a pesquisa bibliográfica. Revista. Katálisys. Florianópolis v. 10 n. esp, 2007.

RAICHELIS. R.. Democratizar a Gestão das Políticas Sociais - Um Desafio a Ser Enfrentado pela Sociedade Civil. In: MOTA, A. E. et al. (orgs.). Serviço Social e Saúde: formação e trabalho profissional. $2^{\mathrm{a}}$ ed. São Paulo: OPAS, OMS, Ministério da Saúde, 2009. 